\title{
Interleukin-17A Levels Vary in Relapsing-Remitting Multiple Sclerosis Patients in Association with Their Age, Treatment and the Time of Evolution of the Disease
}

\author{
José de Jesús Guerrero-García ${ }^{a, b}$ Víctor Andrés Castañeda-Moreno ${ }^{b}$ \\ Norma Torres-Carrillo ${ }^{b}$ José Francisco Muñoz-Valle ${ }^{b}$ Oscar Kurt Bitzer-Quintero ${ }^{c}$ \\ María Dolores Ponce-Regalado ${ }^{\mathrm{e}}$ Mario Alberto Mireles-Ramírez ${ }^{\mathrm{d}}$ \\ Yeminia Valle $^{b}$ Daniel Ortuño-Sahagún ${ }^{b}$ \\ ${ }^{a}$ Doctorado en Ciencias Biomédicas (DCBM), CUCS and b Instituto de Investigación en Ciencias Biomédicas (IICB), CUCS, \\ Universidad de Guadalajara, and ' Laboratorio de Neuroinmunomodulación, Centro de Investigación Biomédica de \\ Occidente (CIBO), and ' Unidad Médica de Alta Especialidad (UMAE), Hospital de Especialidades (HE), Centro Médico \\ Nacional de Occidente (CMNO), Instituto Mexicano del Seguro Social (IMSS), Guadalajara, and e Departamento de \\ Clínicas, División de Ciencias Biomédicas e Ingenierías, Centro Universitario de los Altos, Tepatitlán de Morelos, Mexico
}

\section{Key Words}

Glatiramer acetate $\cdot$ IFN- $\beta \cdot$ IFN- $\gamma \cdot$ IL-10 $\cdot$ IL-17A $\cdot$ Multiple sclerosis

\begin{abstract}
Objective: The present study was specifically designed to discern the possible existence of subgroups of patients with the relapsing-remitting form of multiple sclerosis (RRMS) depending on their gender, age, disease stage (relapsing or remitting), time of disease evolution and response to different treatments. Methods: We analyzed samples from patients with RRMS ( 50 females and 32 males) and healthy individuals (25 matched for age and gender) and determined serum concentrations of IFN- $\gamma$, IL-10 and IL-17A. We stratified patients by gender, age, treatment and disease evolution time, and subsequently correlated these independent variables with the concentrations of the previously mentioned cytokines. Results: We provided initial evidence that treatment
\end{abstract}

exerted possible differential effects depending on the time of disease duration. Results evidence the existence of different subgroups of patients with MS, who can be classified as follows: (a) male or female under or over 40 years of age; (b) disease duration according to treatment (under or over 8 years of disease); (c) classification according to fluctuating levels of IFN- $\gamma$, IL-10 and IL-17A in the following three stages of disease evolution: $<5$ years, between 5 and 10 years, and $>10$ years. Conclusion: These subgroups must be taken into account for the clinical follow-up of patients with MS in order to provide them with a better and more personalized treatment, and also for a deep and detailed analysis of progressive disease, in an attempt to comprehend fluctuations and clinical variability by means of a better understanding of intrinsically physiological variables of the disease.

(c) 2015 S. Karger AG, Basel

José de Jesús Guerrero-García and Víctor Andrés Castañeda-Moreno contributed equally to this work.

\section{KARGER}

E-Mail karger@karger.com

www.karger.com/nim (c) 2015 S. Karger AG, Basel

1021-7401/15/0231-0008\$39.50/0
Daniel Ortuño-Sahagún

Instituto de Investigación en Ciencias Biomédicas (IICB)

CUCS, Universidad de Guadalajara, PO Box 52-126

Guadalajara 45020, Jalisco (México)

E-Mail dortuno@cucs.udg.mx 


\section{Introduction}

Multiple sclerosis (MS) is a demyelinating disease that mainly affects the central nervous system (CNS) and is immune mediated [1-3]. The progression of MS is characterized by very different evolution patterns and variable rates of disability accumulation. There is a female preponderance in MS [4] and a defining feature comprises its fluctuating disease activity, with the occurrence of clinical relapses separated by periods of clinical stability (remissions) [5]. These latter stages can be prolonged for years, and gender appears to play a critical role in MS development, progression and response to treatment [6]. More than $80 \%$ of patients express a relapsing-remitting form of MS (RRMS), characterized by exacerbations of partially or nearly completely reversible neurological disability.

MS can be considered as a disease with different clinical phenotypes rather than an entity encompassing several distinct diseases [7]. RRMS is characterized by T-cellmediated demyelination [8] involving T-cell subtypes, such as Th1 [9], $\mathrm{T}_{\text {reg }}[10]$ and Th17 $[9,11]$, which characteristically produce interferon (IFN)- $\gamma$, interleukin (IL)10 and IL-17A, respectively. Consequently, these cytokines can be used as markers of the differential activity of the disease during different disease stages and also to monitor the response of the immune system to treatment. Treatment of MS consists of immunomodulatory drugs, such as glatiramer acetate (GA) and IFN- $\beta$, which affect and modulate the autoreactive immune response through cytokine pathways [12] and which comprise the first US Federal Drug Administration-approved treatment for MS [13]. However, the efficiency of these treatments varies widely among different MS patients, and unfortunately there is no cure of MS.

One of the main problems is related to the differential genetic background and also the disparity of epigenetic influences that affect the disease progression. Given that immunological events along relapsing-remitting periods are not well defined, more and novel analyses must be performed to better understand MS pathogenesis and to better comprehend the disparity of response to different treatment approaches by identifying subsets of patients (responders/nonresponders), with better/ poor prognosis, depending on treatment, age, gender and disease evolution time. In the present work, we analyzed samples from 82 RRMS patients (50 females and 32 males) and determined serum concentrations of IFN- $\gamma$, IL-10 and IL-17A. We stratified patients by gender, age, treatment and disease evolution time, and sub-
Table 1. Demographic and clinical data of samples from RRMS patients

\begin{tabular}{lllc}
\hline & Female & Male & Total \\
\hline Patients, $\mathrm{n}$ & 50 & 32 & 82 \\
$\quad$ \% & 61 & 39 & 100 \\
Age, years & $34 \pm 8.5$ & $32 \pm 9.9$ & $33 \pm 9.0$ \\
Disease duration, years & $8.6 \pm 5.2$ & $6.9 \pm 5.3$ & $7.9 \pm 5.3$ \\
EDSS ( $\mathrm{n}=50)$ & 2.3 & 2.7 & 2.5 \\
MSSS (n=48) & 3.1 & 4 & 3.4 \\
\hline
\end{tabular}

Data on age and disease duration are expressed as means \pm SD.

sequently correlated these independent variables with the concentrations of the previously mentioned cytokines, in an attempt to ascertain the existence of different subgroups.

\section{Patients and Methods}

\section{Patients}

A total of 82 patients ( 50 females and 32 males) diagnosed with RRMS (41 in clinical relapse and 41 in clinical remission), who had received IFN- $\beta(n=29)$ and GA $(n=53)$, were recruited from the Neurology Service of the Western National Medical Center's Specialty Hospital of the Mexican Social Security Mexican Institute (IMSS) and the Neurology Service of Guadalajara Civil Hospital in Jalisco, a province of Mexico. Study patients with RRMS fulfilled the following criteria: (1) diagnosed with RRMS according to the revised McDonald diagnostic criteria (2005) [14]; (2) age between 20 and 60 years, and (3) RRMS treated with IFN- $\beta$ or GA for at least 3 months. Clinical disability was evaluated using Kurtzke's [15] Expanded Disability Status Scale (EDSS), and disease severity was evaluated utilizing the MS Severity Score (MSSS) [16]. The clinical form of RRMS was determined according to the classification of Lublin and Reingold [17] published in 1996 and its revision in 2013 [18]. RRMS patients in clinical relapse and those in clinical remission were included. Clinical relapse is defined as an episode of acute worsening of neurologic functions and clinical remission as the period of variable degree of recovery with no relapse episodes occurring within the last 3 months prior to the time of enrollment in this study. Untreated RRMS patients were not included. Patients with the following conditions were excluded: (1) a diagnosis of secondary progressive MS or primary progressive MS; (2) treatment with corticosteroids in the previous 3 months; (3) a clinical history of autoimmune or inflammatory disease, and/or (4) a diagnosis of any other chronic-degenerative disease of the CNS. All patients gave their written informed consent for study inclusion. The control group consisted of 25 age- and gendermatched healthy individuals (15 females and 10 males) that were selected among the general population in the same geographical areas as the patients. The samples were collected at the same time in order to diminish bias associated with the circadian cycle. This study was conducted in accordance with the ethical guidelines of 
Table 2. Serum cytokine levels (pg/ml) of RRMS patients treated with IFN- $\beta$ and GA and grouped by different criteria

\begin{tabular}{|c|c|c|c|c|c|c|}
\hline \multirow[t]{2}{*}{ Subgroups } & \multicolumn{6}{|c|}{ Cytokine levels } \\
\hline & IFN- $\gamma$ & $\mathrm{p}$ value & IL-10 & $\mathrm{p}$ value & IL-17A & $\mathrm{p}$ value \\
\hline \multicolumn{7}{|l|}{ Treatment } \\
\hline IFN- $\beta$ & $28.71 \pm 3.86$ & \multirow{2}{*}{$0.06^{\mathrm{a}}$} & $6.31 \pm 2.35$ & \multirow[t]{2}{*}{$0.20^{\mathrm{a}}$} & $1.87 \pm 0.32$ & \multirow[t]{2}{*}{$0.22^{\mathrm{a}}$} \\
\hline GA & $43.35 \pm 6.58$ & & $9.48 \pm 2.42$ & & $2.09 \pm 0.23$ & \\
\hline \multicolumn{7}{|l|}{ Phase } \\
\hline \multicolumn{7}{|l|}{ Gender } \\
\hline Male & $30.60 \pm 3.61$ & \multirow{2}{*}{$0.09^{a}$} & $7.72 \pm 2.28$ & \multirow[t]{2}{*}{$0.37^{\mathrm{a}}$} & $1.51 \pm 0.24$ & \multirow[t]{2}{*}{$0.02^{\mathrm{a}}$} \\
\hline Female & $43.02 \pm 6.98$ & & $6.84 \pm 1.55$ & & $2.34 \pm 0.26$ & \\
\hline \multicolumn{7}{|c|}{ Disease duration $<8$ years } \\
\hline IFN- $\beta$ & $26.64 \pm 4.20$ & \multirow[t]{2}{*}{$0.03^{\mathrm{a}}$} & $6.99 \pm 3.20$ & \multirow{2}{*}{$0.47^{\mathrm{a}}$} & $1.69 \pm 0.34$ & \multirow[t]{2}{*}{$0.04^{\mathrm{a}}$} \\
\hline GA & $47.83 \pm 9.15$ & & $6.73 \pm 1.27$ & & $2.53 \pm 0.31$ & \\
\hline \multicolumn{7}{|l|}{ Age $<40$ years } \\
\hline Male & $31.94 \pm 4.17$ & \multirow[t]{2}{*}{$0.14^{\mathrm{a}}$} & $7.90 \pm 2.67$ & \multirow[t]{2}{*}{$0.48^{\mathrm{a}}$} & $1.62 \pm 0.27$ & \multirow[t]{2}{*}{$0.08^{a}$} \\
\hline Female & $42.70 \pm 7.98$ & & $7.73 \pm 2.10$ & & $2.20 \pm 0.30$ & \\
\hline \multicolumn{7}{|l|}{ Age $\geq 40$ years } \\
\hline Male & $23.35 \pm 4.30$ & \multirow[t]{2}{*}{$0.44^{\mathrm{b}}$} & $6.74 \pm 2.58$ & \multirow[t]{2}{*}{$0.14^{\mathrm{b}}$} & $0.91 \pm 0.40$ & \multirow[t]{2}{*}{$0.03^{\mathrm{b}}$} \\
\hline Female & $43.83 \pm 14.66$ & & $4.57 \pm 1.05$ & & $2.70 \pm 0.56$ & \\
\hline \multicolumn{7}{|c|}{ Severity (MSSS)/disability (EDSS) } \\
\hline High & $43.71 \pm 9.87$ & \multirow{3}{*}{$0.21^{\mathrm{b}}$} & $7.68 \pm 2.49$ & $0.21^{\mathrm{b}}$ & $1.96 \pm 0.30$ & $0.21^{\mathrm{b}}$ \\
\hline Low & $42.64 \pm 9.18$ & & $9.43 \pm 3.76$ & & $2.57 \pm 0.51$ & \\
\hline Control values & $16.8 \pm 2.42$ & & $2.23 \pm 0.29$ & & $7.30 \pm 0.51$ & \\
\hline
\end{tabular}

Means \pm SEM. Significant $p$ values are italicized. ${ }^{a}$ Student's t test. ${ }^{b}$ Mann-Whitney U test.

the 2013 Declaration of Helsinki and was approved by the Ethical Committee of the IMSS in Mexico.

\section{Blood Sample Collection}

Peripheral blood was collected in BD Vacutainer ${ }^{\circledR}$ tubes without anticoagulant to obtain serum. Serum was obtained by centrifugation and aliquots were immediately stored at $-80^{\circ} \mathrm{C}$ until assayed.

\section{Cytokine Measurements}

Serum cytokine levels (IFN- $\gamma$, IL-10 and IL-17A) were measured with a sandwich enzyme-linked immunosorbent assay using a commercial immunoassay (BioLegend, San Diego, Calif., USA) according to the manufacturer's instructions. Results were expressed in pictograms per milliliter. The specificity and the sensitivity for the cytokines was defined according to the manufacturer's instructions (specificity: except in IL-17A cytokine measurements in which cross-reactivity with human IL-17F was negligible, non-cross-reactivity was observed when those kits were used to analyze multiple human and mouse recombinant cytokines/chemokines at up to $50 \mathrm{ng} / \mathrm{ml}$; sensitivity: the minimum detectable concentrations were $4 \mathrm{pg} / \mathrm{ml}$ for IFN- $\gamma, 2 \mathrm{pg} / \mathrm{ml}$ for IL-10 and $1 \mathrm{pg} /$ $\mathrm{ml}$ for IL-17A).

\section{Statistical Analysis}

A database was created using the Microsoft Office Excel program and statistical analysis was performed using GraphPad Prism version 5.0. Data analyses of cytokine levels were performed by calculating means, SD and SEM. The groups' continuous variables were compared using the Student t test, the Mann-Whitney U test, analysis of variance (ANOVA) or the Kruskal-Wallis test, when appropriate. Statistical significance was considered when $\mathrm{p}<0.05$.

\section{Results}

Demographic and clinical data of the samples from the patients with RRMS are presented in table 1. In addition, mean values obtained from the EDSS and MSSS tests are indicated; it is noteworthy that females exhibited slightly longer disease duration, but they were slightly less affected. Also, disease prevalence in our study population corresponds to previously published results, which show a nearly 3:1 female:male ratio [19]. Additionally, this find-
10

Neuroimmunomodulation 2016;23:8-17 DOI: $10.1159 / 000441004$
Guerrero-García et al. 


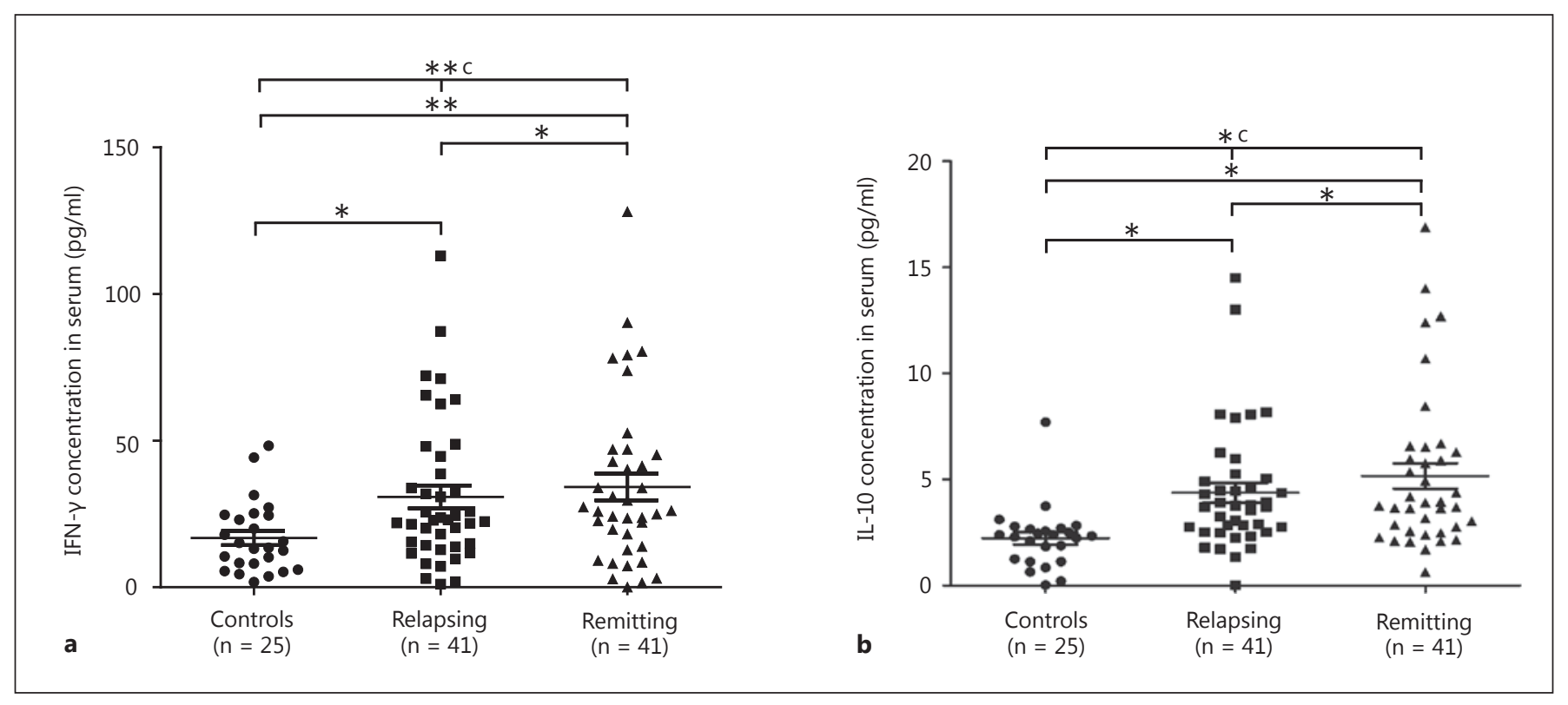

Fig. 1. IFN- $\gamma$ (a) and IL-10 (b) serum levels of RRMS patients. IFN- $\gamma$ and IL-10 tends to increase in remitting compared to relapsing RRMS patients and controls. The dot plots show the concentrations of IFN- $\gamma$ and IL-10 in the serum of controls and RRMS. ${ }^{*} \mathrm{p}<0.05,{ }^{* *} \mathrm{p}<0.01$ (Student's t test); ${ }^{*, \mathrm{c}} \mathrm{p}<0.05,{ }^{* *, \mathrm{c}} \mathrm{p}<0.01$ (ANOVA).

ing agreed with previous reports where women show less progression of disability than men during the disease course [20].

A summary of the results obtained for the concentrations of the three studied cytokines is shown in table 2 . Additionally, table 2 includes the results obtained from the analysis of the different subgroups of patients. First, we divided our study group by treatment: IFN- $\beta(n=29)$ or GA ( $n=53)$. Results showed that IFN- $\gamma$ and IL-10 levels are higher in patients than in controls. Contrariwise, IL-17A levels were lower in patients treated with IFN- $\beta$ or GA than in controls, although none of the three cytokines determined reached statistically significant differences among treatments. Second, we classified samples by disease phase: whether the patients were in the relapsing $(\mathrm{n}=41)$ or remitting $(\mathrm{n}=41)$ phase. According to this classification, it is important to mention that IFN- $\gamma$ (fig. 1a) and IL-10 (fig. 1b) concentrations are increased in patients in the remitting disease phase $(\mathrm{p} \leq 0.05)$, whereas IL-17A presented no differences. Third, we grouped samples by gender: male $(\mathrm{n}=32)$ and female $(\mathrm{n}=50)$, and only IL-17A was increased in females versus males ( $\mathrm{p}<0.05$; fig. 2a).

Based on this initial analysis and on the apparently differential distribution of some of the samples within each of these classifications, we decided to designate dif- ferent subgroups. First, subgroups were distinguished when we classified samples by gender subdivided in two groups by age: one $<40$ years and the other $\geq 40$ years. Under these categories, IFN- $\gamma$ and IL-10 concentrations did not vary, but again, IL-17A concentrations did ( $\mathrm{p}<$ 0.05 ; fig. $2 b$ ), the latter being significantly higher in females than in males $\geq 40$ years of age. In addition, these also tended to increase in females $\geq 40$ years when compared with females $<40$ years of age, but tended to decrease in males $\geq 40$ years when compared with males $<40$ years of age, although this did not reach statistical significance, probably due to the small number of patients aged $\geq 40$ years.

Second, in relation to treatment, we subdivided the groups by disease duration and selected two groups: disease duration $<8$ years $(\mathrm{n}=46)$ and $\geq 8$ years $(\mathrm{n}=36)$. Under these classifications, IL-10 concentrations did not vary, but IFN- $\gamma$ and IL-17A concentrations $\operatorname{did}(\mathrm{p}<0.05$; fig. 3). It is relevant to note that samples from patients treated with IFN- $\beta$ demonstrated an increase in IL-17A levels when these samples derived from patients with disease evolution $\geq 8$ years; however, when patients were treated with GA, IL-17A levels decreased after 8 years of disease duration (fig. 3).

Third, we subclassified the samples by applying values assigned for disability and severity using the EDSS and 
Fig. 2. IL-17A serum levels of RRMS patients classified by gender. a IL-17A concentration is reduced in MS patients compared to controls and tends to be higher in females versus males. b Subjects classified by age in two groups ( $<40$ and $\geq 40$ years). While IL-17A concentrations tend to decrease in aged males, it increased in aged females. n.s. $=$ Nonsignificant; ${ }^{*} \mathrm{p}<0.05$ (Student's t test); *, a $\mathrm{p}<0.05$, ***, a $\mathrm{p}<$ 0.0001 (Mann-Whitney U test); ${ }^{*}$, b $\mathrm{p}<$ $0.05,{ }^{* * *, b} \mathrm{p}<0.0001$ (Kruskal-Wallis test).

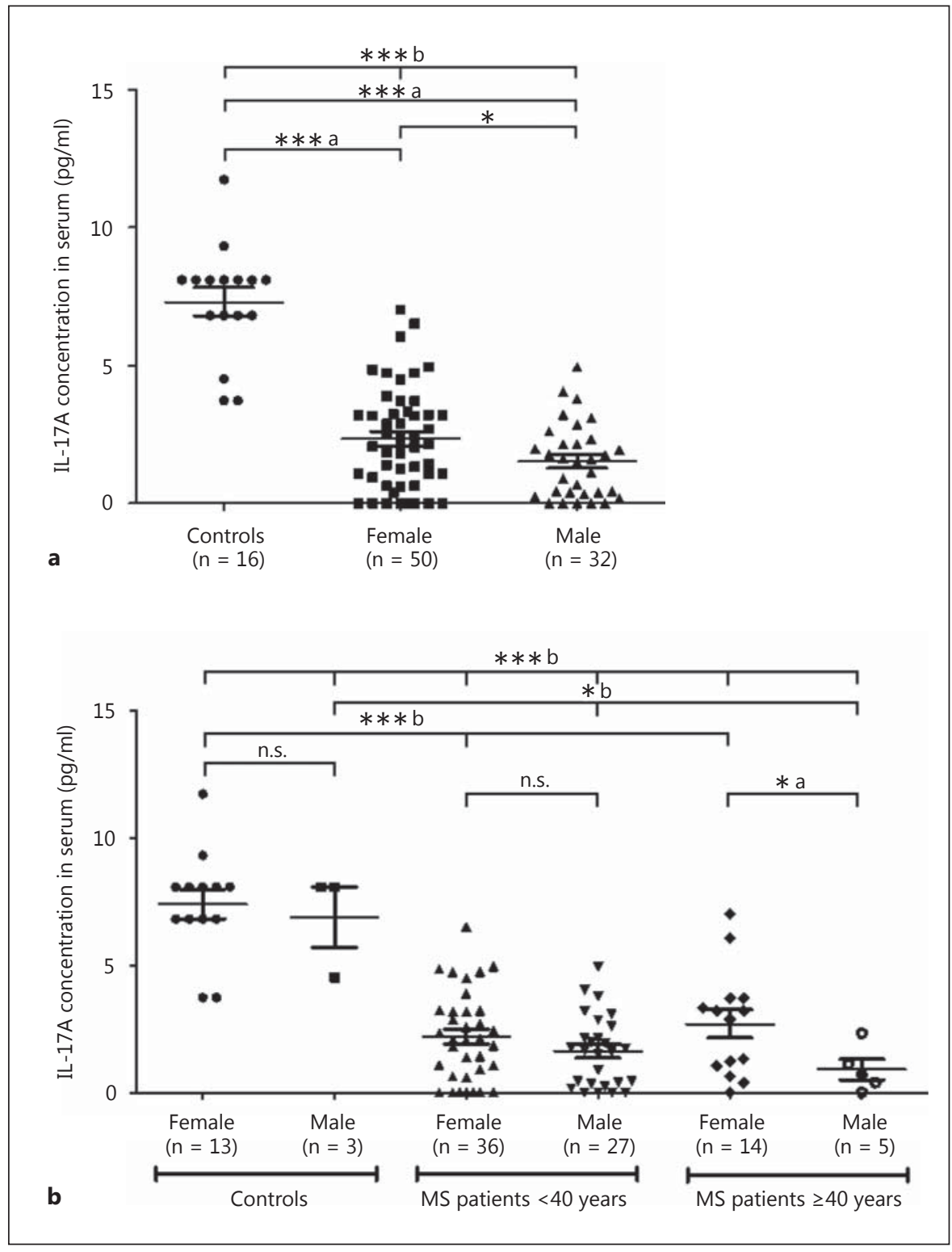

the MSSS test, respectively, assigning patients into one of the following two groups: with high disability and severity, and with low disability and severity. However, none of the cytokines studied significantly varied among these subgroups.

Finally, given the data dispersion of the concentrations of the three cytokines studied, we decided to stratify the data by each year of disease evolution (fig. 4). Under this arrangement, it is noteworthy that the concentration of the three studied cytokines varied among different disease duration years, having a three-wave shape with maximal spikes at around 5 and 10 years (12 years in the case of IL-10) of disease evolution. Prior to and after these peaks, cytokine concentrations decreased significantly.

\section{Discussion}

The present study was specifically designed to discern the possible existence of subgroups of patients with RRMS depending on their gender, age, disease stage (relapsing or remitting), time of disease evolution and response to different treatments based on the serum levels of three 
Fig. 3. IL-17A and IFN- $\gamma$ serum levels in RRMS patients treated with IFN- $\beta$ or GA and classified by disease duration. IL-17A and IFN $-\gamma$ concentrations varied depending on the treatment but only when subjects are grouped by disease duration. a IL17A: ${ }^{*} \mathrm{p}<0.05$ (Student's t test); ${ }^{* *}$, a $\mathrm{p}<$ $0.01, * * *$, a $\mathrm{p}<0.0001$ (Mann-Whitney U test); ${ }^{* * *, b} \mathrm{p}<0.0001$ (Kruskal-Wallis). b IFN- $\gamma:{ }^{*} \mathrm{p}<0.05,{ }^{* *} \mathrm{p}<0.01$ (Student's t test); ${ }^{*} \mathrm{~b} \mathrm{p}<0.05$ (Kruskal-Wallis test).
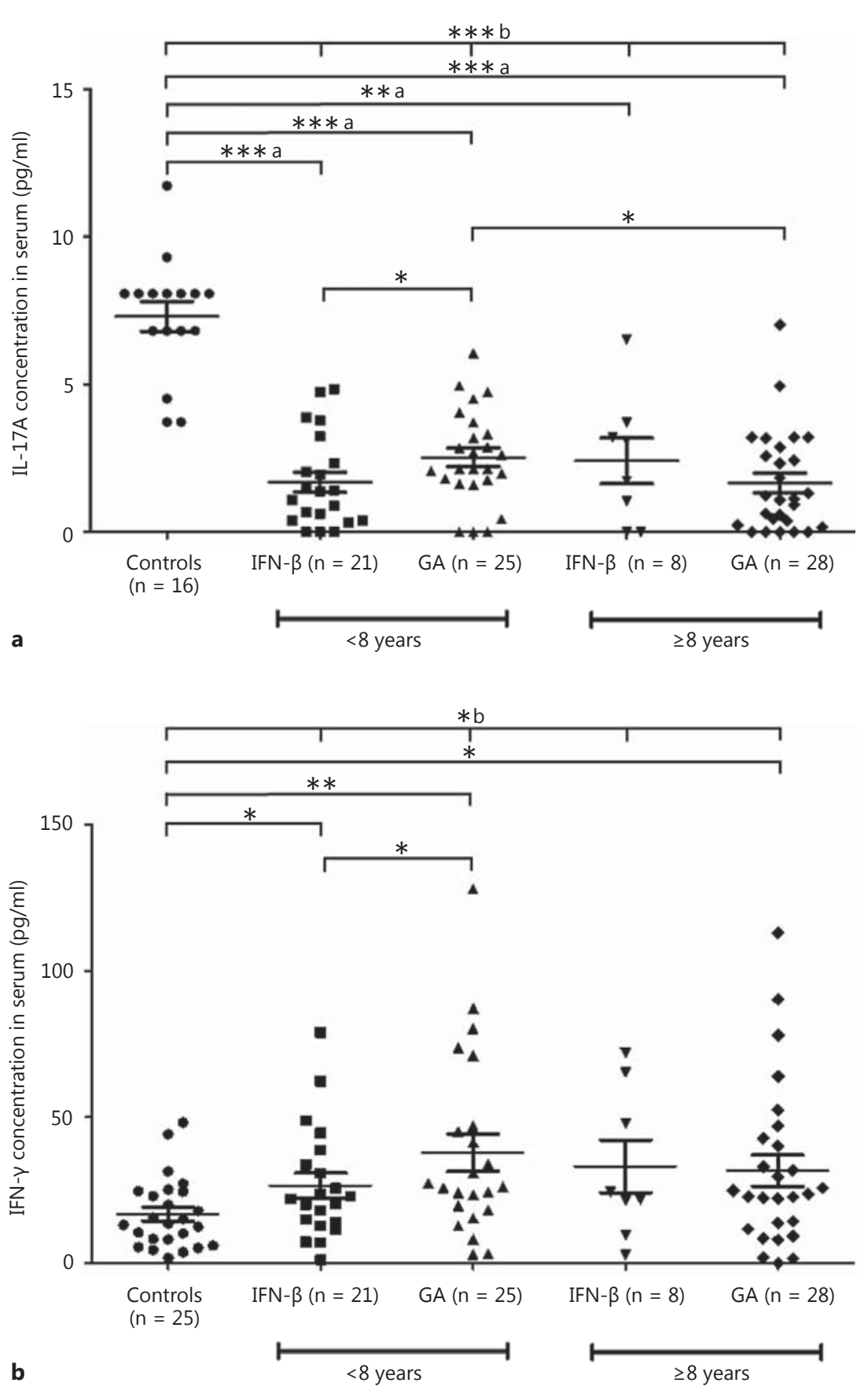

cytokines, IFN- $\gamma$, IL-10 and IL-17A, which helped to monitor the activity of the main T-cell subpopulations involved in the pathophysiology of MS [11,21, 22].

First, our study showed that IFN- $\gamma$ and IL-10 levels tended to be higher in the remitting phase, which probably reflects an immunomodulatory effect that decreases
Th17 cell differentiation $[23,24]$. The increase in IFN- $\gamma$ mediates STAT1 (signal transducer activator of transcription 1) activation, which in turn enhances SOCS3 levels (a Th17 differentiation inhibitor); then, STAT3 phosphorylation is attenuated [25]. On the other hand, IL-10 levels were elevated in MS patients, being higher in 
Fig. 4. IFN- $\gamma$ (a), IL-17A (b) and IL-10 (c) serum levels in RRMS patients distributed by disease duration. Graphics show threewave fluctuations with peaks at around 5 and 10 years of disease development, which tend to decrease after 15 years of evolution.

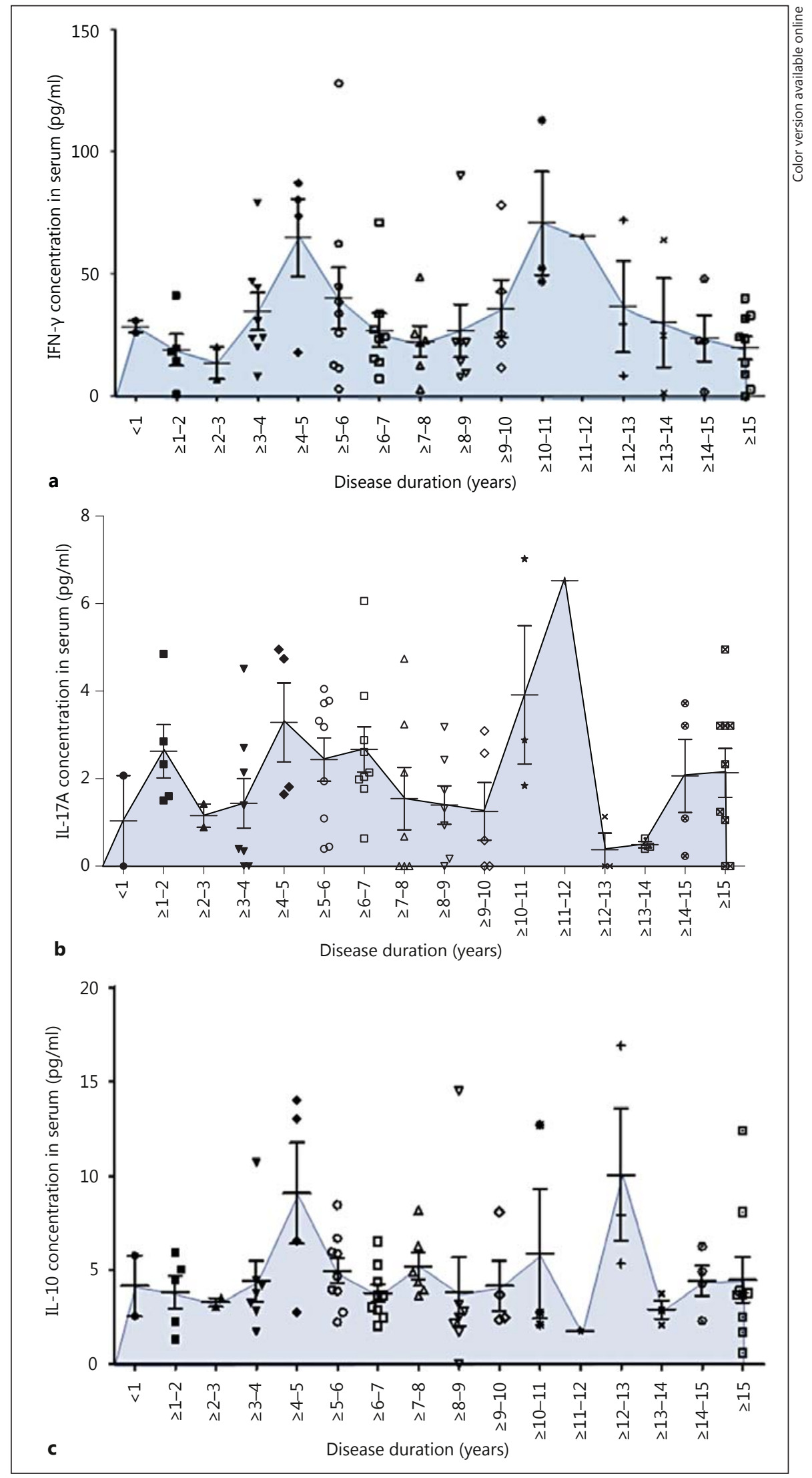


Fig. 5. Variations in IL-17A and IFN- $\gamma$ in RRMS patients are depending on gender and age (a) and treatment and time of evolution of the disease (b).

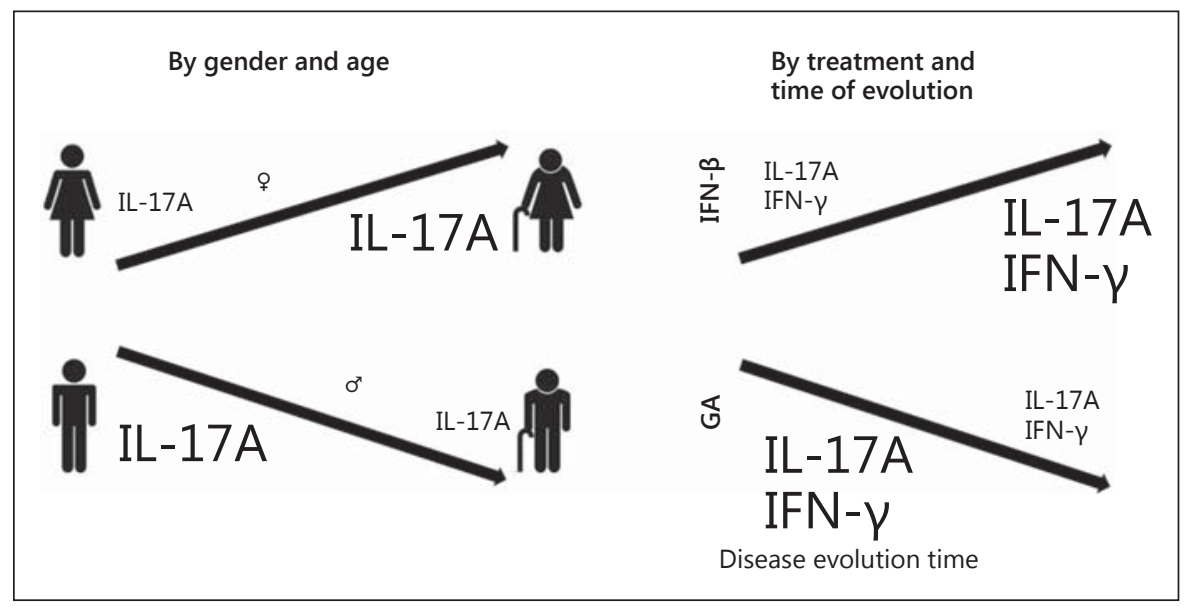

those who are in remission. IL-10 is an immunomodulatory cytokine with predominantly suppressive actions that is produced by many cell types including $\mathrm{T}_{\text {reg }}$ cells [26]. Previous studies indicate that treatment with IFN- $\beta$ or GA induces elevated IL-10 production [27-29], which enhances the immunomodulatory effect in the remission phase in our patients. Therefore, our study provided further support that IFN- $\gamma$ and IL-10 may be involved in the pathophysiology of MS. Consequently, we must take into account whether the patients are in the relapsing or the remitting disease phase in order to interpret clinical analyses based on IFN- $\gamma$ and IL-10 levels.

Second, of note, IL-17A significantly increased in females. Then, after separating samples from patients $<40$ years of age, the subgroup that maintained the statistical significance was the female group aged $\geq 40$ years when compared with the group of males. In addition, we observed that in males, average serum levels of IL-17A tended to decrease in patients $\geq 40$ years, while in females, average serum levels of IL-17A increased, which probably means that the levels of this cytokine are modified by a hormonal component that could lead to an increase in proinflammatory effects and subsequently to clinical exacerbations/manifestations of the disease. Hormonal influences appear to be involved in regulating the balance of cytokine secretion by Th1, Th2 and $\mathrm{T}_{\text {reg }}$ cells, as well as by antigen-presenting cells [30]. Additionally, some studies have been associated with a differential response of $\mathrm{T}$ cells to sex hormones in vitro and in vivo in patients with MS, revealing that progesterone and estradiol enhance $\mathrm{T}_{\text {reg }}$ function [31,32]. Also, the late stages of pregnancy are associated with a decrease in clinical symptoms or relapse rates in MS patients and animal models of MS [33]; moreover, IL-17A serum levels are associated with estro- gen deficiency in postmenopausal women [34]. Taken together, this evidence suggests that hormonal stage plays an important role in the secretion of the proinflammatory cytokine IL-17A. However, it is necessary to conduct future studies on the relationship between IL-17A serum levels and the effect of hormones on the pathogenesis of MS.

Third, but more relevant, we also provided initial evidence that treatment exerted possible differential effects depending on the time of disease duration, because serum levels of IL-17A differed between patients with disease duration $<8$ and $\geq 8$ years, being lower in patients treated with IFN- $\beta$ with disease duration $<8$ years; however, thereafter, IL-17A levels increased in patients treated with IFN- $\beta$, while they decreased in GA-treated patients. Among the proinflammatory cytokines involved in MS pathophysiology, IL-17A has gained attention in recent years owing to its ability to promote the transmigration of human CD4+ lymphocytes through the blood-brain barrier endothelial cells by disrupting tight junctions [11]. Furthermore, Th17 cells that release IL-17A might enhance glutamate excitotoxicity as an effector mechanism in MS pathogenesis [35]. Additionally, high levels of IL-17A are associated with several chronic inflammatory diseases, including rheumatoid arthritis, psoriasis and MS [36]; however, to the best of our knowledge, IL-17 fluctuations have not been reported previously. This could be relevant in terms of the different disease stages and the variability in disease extent.

In the same direction, our results showed lowest levels of IFN- $\gamma$ in patients with $<8$ years of disease duration treated with IFN- $\beta$ when compared with GA treatment. It has been documented that IFN- $\gamma$ induces apoptosis in human oligodendrocytes contributing to MS pathophys- 
iology by increasing the number of exacerbations $[37,38]$. An earlier report documented that IFN- $\beta$ therapy for 1 year diminished IFN- $\gamma$ expression without significant changes in IL-17A [39]. In this sense, IFN- $\beta$ seems to be more useful in the first years of disease treatment, but further studies in a larger patient cohort are needed in order to test this hypothesis.

In a recent study in 2015, Pasquali et al. [40] reported a negative correlation between EDSS and IL-17 serum levels, and a decrease in this cytokine when comparing patients who were 'non-active' (remitting) versus 'active' (relapsing). In contrast, we found higher levels of IL-17A in the relapsing versus the remitting phase, and we were unable to find any significant correlation between EDSS and IL-17A levels (nor between those of IL-10 or IFN- $\gamma$ ). This could be partially explained by the different inclusion criteria for both studies because, in our case, selected patients had been free of corticosteroid treatment for at least 3 months, while in the previously mentioned work, the authors selected patients with only 1 month without corticosteroid treatment; thus, it is possible that the system can continue to be influenced by the corticosteroid effect. Additionally, these authors included a small group of patients ( 9 males and 21 females), while our sample was larger ( 32 males and 50 females), that is more than three times the number of males and more than double the number of females. Despite these differences between studies, both coincide in the conclusion regarding the physiological and clinical relevance of the altered cytokine profiles in patients with MS. Therefore, further studies are necessary, including meta-analyses, in larger numbers of patients with more accurate clinical characterization and more precise categorization in subgroups, as we proposed, to avoid heterogeneous and conflicting results.

Finally, because we detected a wide range of the serum levels of the three cytokines studied, we performed an analysis by separating samples by each disease evolution year (between 1 and 15 years) in an attempt to ascertain whether there was some correlation or fluctuating variations. As we expected, we found a three-wave profile for all three cytokines tested, which probably reflects the physiological cyclical variations between the relapsing and remitting stages of the disease and which could help to improve monitoring of the disease progression.

In conclusion, our study provides compelling evidence of the existence of different subgroups of patients with MS, who can be classified as follows: (a) age and gender, male or female $<40$ or $\geq 40$ years of age; (b) disease duration according to treatment in both groups: under or over 8 years of disease evolution; (c) disease duration according to fluctuating levels of at least the three cytokines reported here (IFN- $\gamma$, IL-10 and IL-17A) in three stages: $<5$ years; between 5 and 10 years, and $>10$ years (summarized in fig. 5). These subgroups must be taken into consideration for the clinical follow-up of patients with MS in order to provide them with improved and more personalized treatment, and also for a deep and detailed analysis of disease progression in an attempt to understand the fluctuations in the disease and clinical variability through a better understanding of its intrinsically physiological variables.

\section{Acknowledgments}

We thank all of the patients for participating in the study. The study was partially supported by Universidad de Guadalajara (grant 222769 PRO-SNI 2014 to D.O.-S.); fellowship support was provided by CONACyT-México grants 2014-305861 to J.d.J.G.-G.

\section{Disclosure Statement}

The authors declare that the research was conducted in the absence of any commercial or financial relationships that could be construed as a potential conflict of interest.

\section{References}

1 Noseworthy JH, Lucchinetti C, Rodriguez M, Weinshenker BG: Multiple sclerosis. N Engl J Med 2000;343:938-952.

$\checkmark 2$ Bruck W: The pathology of multiple sclerosis is the result of focal inflammatory demyelination with axonal damage. J Neurol 2005; 252(suppl 5):v3-v9.

-3 Lassmann H: Multiple sclerosis: lessons from molecular neuropathology. Exp Neurol 2014; 262(pt A):2-7.

4 Compston A, Coles A: Multiple sclerosis. Lancet 2002;359:1221-1231.
5 Sospedra M, Martin R: Immunology of multiple sclerosis. Annu Rev Immunol 2005;23: 683-747.

-6 Irizar H, Munoz-Culla M, Sepulveda L, Saenz-Cuesta M, Prada A, Castillo-Trivino T, Zamora-Lopez G, de Munain AL, Olascoaga J, Otaegui D: Transcriptomic profile reveals gender-specific molecular mechanisms driving multiple sclerosis progression. PLoS One 2014;9:e90482.
16
Neuroimmunomodulation 2016;23:8-17 DOI: $10.1159 / 000441004$
7 Confavreux C, Vukusic S: Natural history of multiple sclerosis: implications for counselling and therapy. Curr Opin Neurol 2002;15: 257-266.

8 Neumann H, Medana IM, Bauer J, Lassmann $\mathrm{H}$ : Cytotoxic T lymphocytes in autoimmune and degenerative CNS diseases. Trends Neurosci 2002;25:313-319.

9 Lovett-Racke AE, Yang Y, Racke MK: Th1 versus Th17: are $\mathrm{T}$ cell cytokines relevant in multiple sclerosis? Biochim Biophys Acta 2011;1812:246-251. 
10 Buc M: Role of regulatory T cells in pathogenesis and biological therapy of multiple sclerosis. Mediators Inflamm 2013;2013:963748.

-11 Kebir H, Kreymborg K, Ifergan I, DodeletDevillers A, Cayrol R, Bernard M, Giuliani F, Arbour N, Becher B, Prat A: Human TH17 lymphocytes promote blood-brain barrier disruption and central nervous system inflammation. Nat Med 2007;13:1173-1175.

12 Dhib-Jalbut S: Mechanisms of action of interferons and glatiramer acetate in multiple sclerosis. Neurology 2002;58:S3-S9.

$\checkmark 13$ Minagar A: Current and future therapies for multiple sclerosis. Scientifica 2013;2013: 249101.

-14 Polman CH, Reingold SC, Edan G, Filippi M, Hartung HP, Kappos L, Lublin FD, Metz LM, McFarland HF, O'Connor PW, SandbergWollheim M, Thompson AJ, Weinshenker BG, Wolinsky JS: Diagnostic criteria for multiple sclerosis: 2005 revisions to the 'McDonald Criteria'. Ann Neurol 2005;58:840-846.

15 Kurtzke JF: Rating neurologic impairment in multiple sclerosis: an expanded disability status scale (EDSS). Neurology 1983;33:14441452.

-16 Roxburgh RH, Seaman SR, Masterman T, Hensiek AE, Sawcer SJ, Vukusic S, Achiti I, Confavreux C, Coustans M, le Page E, Edan G, McDonnell GV, Hawkins S, Trojano M, Liguori M, Cocco E, Marrosu MG, Tesser F, Leone MA, Weber A, Zipp F, Miterski B, Epplen JT, Oturai A, Sorensen PS, Celius EG, Lara NT, Montalban X, Villoslada P, Silva AM, Marta M, Leite I, Dubois B, Rubio J, Butzkueven H, Kilpatrick T, Mycko MP, Selmaj KW, Rio ME, Sa M, Salemi G, Savettieri G, Hillert J, Compston DA: Multiple sclerosis severity score: using disability and disease duration to rate disease severity. Neurology 2005;64:1144-1151.

17 Lublin FD, Reingold SC: Defining the clinical course of multiple sclerosis: results of an international survey. National Multiple Sclerosis Society (USA) Advisory Committee on Clinical Trials of New Agents in Multiple Sclerosis. Neurology 1996;46:907-911.

$\checkmark 18$ Lublin FD, Reingold SC, Cohen JA, Cutter GR, Sorensen PS, Thompson AJ, Wolinsky JS, Balcer LJ, Banwell B, Barkhof F, Bebo B Jr, Calabresi PA, Clanet M, Comi G, Fox RJ, Freedman MS, Goodman AD, Inglese $M$, Kappos L, Kieseier BC, Lincoln JA, Lubetzki C, Miller AE, Montalban X, O'Connor PW, Petkau J, Pozzilli C, Rudick RA, Sormani MP, Stuve O, Waubant E, Polman CH: Defining the clinical course of multiple sclerosis: the 2013 revisions. Neurology 2014;83:278-286.
19 Kingwell E, Marriott JJ, Jette N, Pringsheim T, Makhani N, Morrow SA, Fisk JD, Evans C, Beland SG, Kulaga S, Dykeman J, Wolfson C, Koch MW, Marrie RA: Incidence and prevalence of multiple sclerosis in Europe: a systematic review. BMC Neurol 2013;13:128.

20 Bergamaschi R: Prognostic factors in multiple sclerosis. Int Rev Neurobiol 2007;79:423-447.

21 Amedei A, Prisco D, D’Elios MM: Multiple sclerosis: the role of cytokines in pathogenesis and in therapies. Int J Mol Sci 2012;13:1343813460.

22 Luchtman DW, Ellwardt E, Larochelle C, Zipp F: IL-17 and related cytokines involved in the pathology and immunotherapy of multiple sclerosis: current and future developments. Cytokine Growth Factor Rev 2014;25: 403-413.

23 Harrington LE, Hatton RD, Mangan PR, Turner H, Murphy TL, Murphy KM, Weaver CT: Interleukin 17-producing CD4+ effector $\mathrm{T}$ cells develop via a lineage distinct from the T helper type 1 and 2 lineages. Nat Immunol 2005;6:1123-1132.

24 Damsker JM, Hansen AM, Caspi RR: Th1 and Th17 cells: adversaries and collaborators. Ann NY Acad Sci 2010;1183:211-221.

25 Knosp CA, Johnston JA: Regulation of CD4+ T-cell polarization by suppressor of cytokine signalling proteins. Immunology 2012;135: 101-111.

26 Kvarnstrom M, Ydrefors J, Ekerfelt C, Vrethem M, Ernerudh J: Longitudinal interferonbeta effects in multiple sclerosis: differential regulation of IL-10 and IL-17a, while no sustained effects on IFN-gamma, IL-4 or IL-13. Neurol Sci 2013;325:79-85.

27 Ozenci V, Kouwenhoven M, Huang YM, Xiao B, Kivisakk P, Fredrikson S, Link H: Multiple sclerosis: levels of interleukin-10-secreting blood mononuclear cells are low in untreated patients but augmented during interferon-beta-1b treatment. Scand J Immunol 1999;49: 554-561.

28 Putheti P, Soderstrom M, Link H, Huang YM: Effect of glatiramer acetate (Copaxone) on $\mathrm{CD} 4+\mathrm{CD} 25$ high $\mathrm{T}$ regulatory cells and their IL-10 production in multiple sclerosis. J Neuroimmunol 2003;144:125-131.

29 Ersoy E, Kus CN, Sener U, Coker I, Zorlu Y: The effects of interferon-beta on interleukin-10 in multiple sclerosis patients. Eur J Neurol 2005;12:208-211.
30 van den Broek HH, Damoiseaux JG, De Baets $\mathrm{MH}$, Hupperts RM: The influence of sex hormones on cytokines in multiple sclerosis and experimental autoimmune encephalomyelitis: a review. Mult Scler 2005;11:349-359.

- 31 El-Etr M, Ghoumari A, Sitruk-Ware R, Schumacher M: Hormonal influences in multiple sclerosis: new therapeutic benefits for steroids. Maturitas 2011;68:47-51.

32 Aristimuno C, Teijeiro R, Valor L, Alonso B, Tejera-Alhambra M, de Andres C, Minarro DO, Lopez-Lazareno N, Faure F, Sanchez-Ramon S: Sex-hormone receptors pattern on regulatory T-cells: clinical implications for multiple sclerosis. Clin Exp Med 2012;12: 247-255.

33 Nicot A: Gender and sex hormones in multiple sclerosis pathology and therapy. Front Biosci (Landmark Ed) 2009;14:4477-4515.

34 Molnar I, Bohaty I, Somogyine-Vari E: High prevalence of increased interleukin-17a serum levels in postmenopausal estrogen deficiency. Menopause 2014;21:749-752.

35 Kostic M, Dzopalic T, Zivanovic S, Zivkovic N, Cvetanovic A, Stojanovic I, Vojinovic S, Marjanovic G, Savic V, Colic M: IL-17 and glutamate excitotoxicity in the pathogenesis of multiple sclerosis. Scand J Immunol 2014; 79:181-186.

36 Murata M, Fujimoto M, Matsushita T, Hamaguchi Y, Hasegawa M, Takehara K, Komura $\mathrm{K}$, Sato S: Clinical association of serum interleukin-17 levels in systemic sclerosis: is systemic sclerosis a Th17 disease? J Dermatol Sci 2008;50:240-242.

-37 Pouly S, Becher B, Blain M, Antel JP: Interferon-gamma modulates human oligodendrocyte susceptibility to Fas-mediated apoptosis. J Neuropathol Exp Neurol 2000;59:280-286.

38 Vartanian T, Li Y, Zhao M, Stefansson K: Interferon-gamma-induced oligodendrocyte cell death: implications for the pathogenesis of multiple sclerosis. Mol Med 1995;1:732743.

39 Drulovic J, Savic E, Pekmezovic T, Mesaros S, Stojsavljevic N, Dujmovic-Basuroski I, Kostic J, Vasic V, Mostarica Stojkovic M, Popadic D: Expression of Th1 and Th17 cytokines and transcription factors in multiple sclerosis patients: does baseline T-bet mRNA predict the response to interferon-beta treatment? J Neuroimmunol 2009;215:90-95.

-40 Pasquali L, Lucchesi C, Pecori C, Metelli MR, Pellegrini S, Iudice A, Bonuccelli U: A clinical and laboratory study evaluating the profile of cytokine levels in relapsing remitting and secondary progressive multiple sclerosis. J Neuroimmunol 2015;278:53-59. 